\title{
Molecular Analysis of Turfgrass Rusts Reveals the Widespread Distribution of Puccinia coronata as a Pathogen of Kentucky Bluegrass in the United States
}

Lisa A. Beirn, Melinda Moy, William A. Meyer, and Bruce B. Clarke, Rutgers University, Department of Plant Biology and Pathology, New Brunswick, NJ 08901; and Jo Anne Crouch, United States Department of Agriculture-Agricultural Research Service, Systematic Mycology and Microbiology Laboratory, Beltsville, MD 20705

\begin{abstract}
Beirn, L. A., Moy, M., Meyer, W. A., Clarke, B. B., and Crouch, J. A. 2011. Molecular analysis of turfgrass rusts reveals the widespread distribution of Puccinia coronata as a pathogen of Kentucky bluegrass in the United States. Plant Dis. 95:1547-1557.

Over the past 10 years, rust diseases have become increasingly prevalent on certain cultivars of Kentucky bluegrass. This pattern suggests that new races or new species of rust fungi may have emerged. To test this hypothesis, 66 samples of turfgrass rust fungi collected from across the United States were evaluated based on sequences of the internal transcribed spacer (ITS)-5.8S rDNA region. Phylogenetic analysis revealed three species: Puccinia coronata, $P$. graminis, and $P$. striiformis, comprising 67,28 , and $5 \%$ of the samples, respectively. $P$. coronata was frequently found in association with Kentucky bluegrass, a host-pathogen relationship that has not been previously reported. Comparison of molecular analyses with the use of standard field

identification techniques-host association and pustule pigmentationshowed that $58 \%$ of the Kentucky bluegrass samples would have been incorrectly diagnosed using nonmolecular criteria. To avoid such misidentifications, a real-time polymerase chain reaction diagnostic protocol was developed for turfgrass-associated $P$. graminis, $P$. coronata, and $P$. striiformis using ITS sequences. Accurate, reproducible, species-specific identifications were made using as few as 50 to 150 urediniospores, even in mixed infections. This study represents the first DNA-based evaluation of turfgrass rust fungi and provides a quick and reliable sequence-based protocol as an alternative to less reliable fieldbased identification techniques.
\end{abstract}

Rust is a common fungal disease of cultivated turfgrass that can occur in all turf species and is found worldwide (40). Multiple fungi are responsible for rust symptoms in turf. In temperate regions, the most prevalent turf rust fungi are Puccinia graminis Pers. (causes stem rust), $P$. striiformis Westend. (stripe rust), $P$. coronata Corda (crown rust), and $P$. recondita Dietel \& Holw. and P. brachypodii G.H. Otth (leaf rust) (40). Diseased grasses typically exhibit an unsightly orange-brown discoloration, resulting in aesthetically unattractive turf that is unmarketable in sod production and often unacceptable in athletic fields, home lawns, and golf courses. Over time, diseased areas may die out completely due to decreased photosynthetic rates and increased dark respiration initiated by the fungus (13). Although fungicides can be used to minimize disease by limiting urediniospore production, chemical control is costly and sometimes ineffective (40). As a result, resistance in turfgrass cultivars is used as an important mode of defense against rust pathogens.

Over the past 10 years, turfgrass breeders have documented a gradual shift in susceptibility to rust among Kentucky bluegrass (Poa pratensis L.) cultivars, particularly the 'Midnight' types (10). Once highly resistant to rust, these cultivars are now experiencing a greater incidence of disease. Resistance to rust in Kentucky bluegrass is not well understood, and traditional breeding methods

Corresponding author: J. A. Crouch,

E-mail: joanne.crouch@ars.usda.gov

Mention of a trademark name or proprietary product does not constitute a guarantee by the United States Department of Agriculture.

* The $e$-Xtra logo stands for "electronic extra" and indicates that two supplementary tables and one supplementary figure are available online.

Accepted for publication 16 June 2011.

doi:10.1094/PDIS-01-11-0073

This article is in the public domain and not copyrightable. It may be freely reprinted with customary crediting of the source. The American Phytopathological Society, 2011. remain the standard approach for incorporating disease resistance in turfgrass hosts (10). As has been reported in other grass and cereal systems, turfgrass rust resistance is likely the result of a single dominant gene in the host that matches an avirulence gene in the pathogen $(7,11,12,31,35)$, although different genes may be required for specific fungal races of rust, and other environmental or host factors may also be important (39). Breakdown of rust resistance in wheat (Triticum aestivum L.) typically signals the emergence of a new race (34), and these new phenotypes may emerge frequently in pathosystems where the sexual cycle can be completed. It has been suggested that the emergence of novel race pathotypes, as seen in the wheat rust pathosystem, may be responsible for the shift in cultivar susceptibility observed in Kentucky bluegrass turf (10), but this prediction has not yet been tested. Pathotype specificity has been demonstrated for different isolates of Puccinia graminis in perennial ryegrass (Lolium perenne L.) turf (37) and is suspected for isolates of P. coronata pathogenic to this species $(28,38,41)$. However, these observations were strictly qualitative and, to date, rust pathogen genotyping has not been performed from any turfgrass hosts.

Unlike the cereal rust pathosystems, the cohort of fungal species that are responsible for rust diseases of turfgrasses have not been well studied. The last comprehensive review of rusts on turf-type grasses was completed nearly 30 years ago (18) and predated the use of molecular techniques. Currently, there are a total of 39 species of Puccinia, Physopella, and Uromyces that have been described on turfgrasses based on morphological distinctiveness (40). The number of accepted rust species varies between studies, because morphological characteristics and host plant association (40) are the primary mode of identifying turfgrass rusts, and interpretation of these characteristics can vary depending on the taxonomic treatment used. The use of morphology for rust fungus identification is complicated, because subtle differences such as teliospore size, shape, and pedicel type (33) can vary between closely related species. Moreover, in many instances, only urediniospores are present on the host, a less distinctly shaped spore type that makes accurate morphological identifications difficult and sometimes impossible.

As with morphology, the use of host plant associations to identify rust fungus species can also be problematic. Complete lifecy- 
cles are unknown for many graminicolous rust fungi, making it impossible to fully describe host ranges (3), and cross-infectivity between hosts has been reported in inoculation studies (36). Despite the uncertainty associated with the use of host identity and spore phenotype for rust fungus species identification, these techniques are routinely used in the field, because they are the only tools currently available to breeders and turfgrass managers.

Sequence analysis of the internal transcribed spacer (ITS) region has been used to differentiate between closely related rust fungi $(4,5,9,17,23,45)$; however, to our knowledge, there has never been a DNA-based evaluation of species causing rust diseases in turfgrass hosts. Therefore, our objectives were to use sequencebased phylogenetic analysis of the ITS-5.8S rDNA region to identify fungal species responsible for rust diseases in turfgrasses, and to test the prediction that the shift in rust susceptibility observed among Kentucky bluegrass cultivars in the field is the result of novel species or race associations. We surveyed a range of diseased turfgrass hosts to assess molecular variability of the ITS-5.8S region in rust fungi associated with several commercially important turfgrass species. As an alternative to using morphological

Table 1. Sources of rust fungal samples used in this study and GenBank accession numbers for the rDNA internal transcribed spacer-5.8S sequences

\begin{tabular}{|c|c|c|c|c|}
\hline Isolate & Host species & Origin & Accession number & Reference $^{\mathbf{a}}$ \\
\hline \multicolumn{5}{|c|}{ Puccinia coronata } \\
\hline CR-1 & Arrhenatherum elatius & Czech Republic & DQ355443 & Mycoscience \\
\hline MNCL-1 & Avena sativa & Minnesota & AY114290 & Mycoscience \\
\hline UK-2 & Avena sp. & United Kingdom & GU598105 & $\ldots$ \\
\hline UK-5 & Avena sp. & United Kingdom & GU598106 & $\ldots$ \\
\hline UKF-12 & Avena sp. & United Kingdom & GU598109 & $\ldots$ \\
\hline SLV-1 & Bromus erectus & Slovakia & DQ355449 & Mycoscience \\
\hline CR-2 & B. erectus & Czech Republic & DQ355450 & Mycoscience \\
\hline MNCL-9 & B. inermis & United States & DQ355448 & Mycoscience \\
\hline MNCL-10 & B. inermis & United States & DQ355446 & Mycoscience \\
\hline MI-1 & Bromus sp. & Michigan & GU598069 & $\ldots$ \\
\hline UKF-8 & Calamagrostis sp. & United Kingdom & GU598107 & $\ldots$ \\
\hline UKF-10 & Calamagrostis sp. & United Kingdom & GU598108 & $\ldots$ \\
\hline NJA-24 & Deschampsia sp. & New Jersey & GU598078 & $\ldots$ \\
\hline MNCL-2 & Elytrigia repens & Minnesota & DQ414723 & Mycoscience \\
\hline MNCL-3 & E. repens & Minnesota & DQ414724 & Mycoscience \\
\hline MS-1 & Festuca arundinacea & Mississippi & GU598056 & $\ldots$ \\
\hline NJA-66 & F. arundinacea & New Jersey & GU598047 & $\ldots$ \\
\hline NJA-67 & F. arundinacea & New Jersey & GU598048 & $\ldots$ \\
\hline NJA-9 & Festuca sp. & New Jersey & GU598072 & $\ldots$ \\
\hline IR-1 & Holcus lanatus & Ireland & DQ355444 & Mycoscience \\
\hline UO-1 & Hordeum vulgare & Unknown & DQ355454 & Mycoscience \\
\hline $\mathrm{CH}-1$ & Lolium perenne & Chile & GU598061 & $\ldots$ \\
\hline $\mathrm{CH}-3$ & L. perenne & Chile & GU598062 & $\ldots$ \\
\hline CT-3 & L. perenne & Connecticut & GU598059 & $\ldots$ \\
\hline MA-1 & L. perenne & Massachusetts & GU598063 & $\ldots$ \\
\hline MA-2 & L. perenne & Massachusetts & GU598064 & $\ldots$ \\
\hline MA-3 & L. perenne & Massachusetts & GU598065 & $\ldots$ \\
\hline NJC-7 & L. perenne & New Jersey & GU598079 & $\ldots$ \\
\hline NJCC-31 & L. perenne & New Jersey & GU598083 & $\ldots$ \\
\hline NJCC-33 & L. perenne & New Jersey & GU598084 & $\ldots$ \\
\hline CR-3 & L. perenne & Czech Republic & DQ355441 & Mycoscience \\
\hline UK-3 & L. perenne & United Kingdom & GU598049 & $\ldots$ \\
\hline UKF-13 & L. perenne & United Kingdom & GU598110 & $\ldots$ \\
\hline UKF-14 & L. perenne & United Kingdom & GU598111 & $\ldots$ \\
\hline NJNB-37 & Poa pratensis & New Jersey & GU598091 & $\ldots$ \\
\hline NJCC-42 & P. pratensis & New Jersey & GU598085 & $\ldots$ \\
\hline NJE-50 & P. pratensis & New Jersey & GU598086 & $\ldots$ \\
\hline MEG-1 & P. pratensis & Maine & GU598068 & BPI881581 \\
\hline WY-1 & P. pratensis & Wyoming & GU598112 & $\ldots$ \\
\hline $\mathrm{NC}-2$ & P. pratensis & North Carolina & GU598070 & $\ldots$ \\
\hline $\mathrm{OH}-3$ & P. pratensis & Ohio & GU598098 & $\ldots$ \\
\hline $\mathrm{OH}-4$ & P. pratensis & Ohio & GU598099 & $\ldots$ \\
\hline OH-5 & P. pratensis & Ohio & GU598100 & $\ldots$ \\
\hline MA-4 & P. pratensis & Massachusetts & GU598066 & $\ldots$ \\
\hline MA-5 & P. pratensis & Massachusetts & GU598067 & $\ldots$ \\
\hline NJA-19 & P. pratensis & New Jersey & GU598075 & $\ldots$ \\
\hline NJA-20 & P. pratensis & New Jersey & GU598076 & $\ldots$ \\
\hline NJA-21 & P. pratensis & New Jersey & GU598077 & $\ldots$ \\
\hline NJA-23 & P. pratensis & New Jersey & GU598054 & $\ldots$ \\
\hline NJC-28 & P. pratensis & New Jersey & GU598081 & $\ldots$ \\
\hline NJC-29 & P. pratensis & New Jersey & GU598082 & $\ldots$ \\
\hline NJHP-32 & P. pratensis & New Jersey & GU598090 & $\ldots$ \\
\hline NJT-4 & P. pratensis & New Jersey & GU598092 & $\ldots$ \\
\hline $\mathrm{OH}-1 \mathrm{~B}$ & P. pratensis & Ohio & GU598097 & $\ldots$ \\
\hline $\mathrm{OH}-8 \mathrm{~B}$ & P. pratensis & Ohio & GU598052 & $\ldots$ \\
\hline MNCL-4 & Rhamnus catharticus & Minnesota & DQ355445 & Mycoscience \\
\hline MNCL-5 & R. catharticus & Minnesota & DQ355447 & Mycoscience \\
\hline \multirow[t]{2}{*}{ MNCL-6 } & R. catharticus & Minnesota & DQ355442 & Mycoscience \\
\hline & & & & (continued on next page) \\
\hline
\end{tabular}

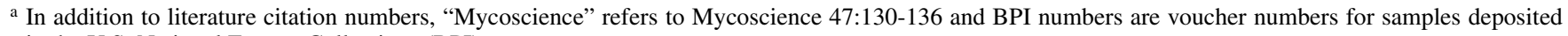
in the U.S. National Fungus Collections (BPI).
} 
characteristics and host plant association for turfgrass rust identification, these sequence data were then used to generate a real-time polymerase chain reaction (PCR) protocol that could be implemented by turfgrass breeding programs and diagnostic laboratories for the quick and accurate identification of turfgrass rust species.

\section{Materials and Methods}

Fungal samples. Eleven grass species symptomatic for rust disease and exhibiting visible urediniospores or teliospores were collected from 13 states in the United States, Australia, Canada, Chile, and the United Kingdom. A complete list of the 66 fungal samples used in this study is presented in Table 1. Upon collection, samples were visually identified to species by urediniospore size, cell wall thickness, and shape and then photographed (data not shown). Tentative morphological identifications of the rust pathogens were made by evaluating 50 urediniospores from each sample. Teliospores were typically absent; however, when present, they were classified by pedicel length, overall shape, cell wall thickness, digitations, and size. Additionally, each sample was evaluated phenotypically for pustule color and orientation (e.g., presence of uredia parallel to leaf veins). Samples were then stored at $4^{\circ} \mathrm{C}$ until

Table 1. (continued from preceding page)

\begin{tabular}{|c|c|c|c|c|}
\hline Isolate & Host species & Origin & Accession number & Reference $^{\mathrm{a}}$ \\
\hline MNCL-7 & R. catharticus & Minnesota & DQ355452 & Mycoscience \\
\hline SLV-2 & R. catharticus & Slovakia & DQ355451 & Mycoscience \\
\hline NJC-8 & Zoysia sp. & New Jersey & GU598080 & $\ldots$ \\
\hline \multicolumn{5}{|c|}{ Puccinia graminis } \\
\hline CR-4 & Anthroxanthum sp. & Czech Republic & DQ417386 & 8 \\
\hline SW-1 & A. sativa & Switzerland & DQ417391 & 8 \\
\hline SW-2 & Dactylis glomerata & Switzerland & DQ417390 & 8 \\
\hline WI-1 & Elymus trachycalus & Wisconsin & DQ417381 & 8 \\
\hline NJF-45 & F. arundinacea & New Jersey & GU598087 & $\ldots$ \\
\hline NJH-48 & F. arundinacea & New Jersey & GU598088 & $\ldots$ \\
\hline NJH-49 & F. arundinacea & New Jersey & GU598089 & $\ldots$ \\
\hline OR-1 & F. arundinacea & Oregon & DQ417385 & 8 \\
\hline OR-2 & L. perenne & Oregon & DQ417384 & 8 \\
\hline UO-2 & L. perenne & unknown & DQ355455 & 8 \\
\hline UO-3 & Lolium sp. & unknown & DQ460726 & 25 \\
\hline MNCL-8 & Phleum pretense & Minnesota & DQ417392 & 8 \\
\hline NJT-5 & Poa pratensis & New Jersey & GU598093 & $\ldots$ \\
\hline NYPI-1 & P. pratensis & New York & GU598095 & $\ldots$ \\
\hline NJGM-39 & P. pratensis & New Jersey & GU598053 & $\ldots$ \\
\hline ONCA-1 & P. pratensis & Canada & GU598103 & $\ldots$ \\
\hline NE-1 & P. pratensis & Nebraska & GU598071 & $\ldots$ \\
\hline NC-1 & P. pratensis & North Carolina & GU598070 & BPI881582 \\
\hline OH-6 & P. pratensis & Ohio & GU598101 & $\ldots$ \\
\hline OH-7 & P. pratensis & Ohio & GU598102 & $\ldots$ \\
\hline MNM-1 & P. pratensis & Minnesota & GU598058 & $\ldots$ \\
\hline NJA-53 & P. pratensis & New Jersey & GU598057 & $\ldots$ \\
\hline NJA-54 & P. pratensis & New Jersey & GU598060 & $\ldots$ \\
\hline NJA-17 & P. pratensis & New Jersey & GU598073 & $\ldots$ \\
\hline NJA-18 & P. pratensis & New Jersey & GU598074 & $\ldots$ \\
\hline $\mathrm{OH}-1 \mathrm{~A}$ & P. pratensis & Ohio & GU598096 & $\ldots$ \\
\hline $\mathrm{OH}-8 \mathrm{~A}$ & P. pratensis & Ohio & GU598051 & $\ldots$ \\
\hline SW-3 & P. pratensis & Switzerland & DQ417389 & 8 \\
\hline KS-1 & Triticum aestivum & Kansas & DQ417374 & 8 \\
\hline OH5-1 & T. aestivum & Ohio & DQ417375 & 8 \\
\hline MX-1 & T. aestivum & Mexico & DQ417377 & 8 \\
\hline OR-3 & T. aestivum & Oregon & DQ417380 & 8 \\
\hline SW-4 & T. aestivum & Switzerland & DQ417387 & 8 \\
\hline SD-1 & T. aestivum & South Dakota & DQ417383 & 8 \\
\hline UO-4 & T. aestivum & Unknown & AY114289 & Mycoscience \\
\hline \multicolumn{5}{|c|}{ Puccinia striiformis } \\
\hline MNC-1 & Berberis chinensis & Minnesota & GU382672 & 8 \\
\hline MNC-5 & B. chinensis & Minnesota & GQ457305 & 27 \\
\hline CR-5 & D. glomerata & Czech Republic & DQ417403 & 27 \\
\hline WA-1 & Hordeum vulgare & Washington & DQ417408 & 8 \\
\hline CA-1 & H. vulgare & California & DQ417402 & 8 \\
\hline PA-2 & L. perenne & Pennsylvania & GU598104 & $\ldots$ \\
\hline NYH-4 & L. perenne & New York & GU598094 & BPI881580 \\
\hline AU-1 & Роа аппиа & Australia & GU598050 & $\ldots$ \\
\hline GA-1 & P. pratensis & Georgia & DQ417407 & 8 \\
\hline MNC-2 & T. aestivum & Minnesota & GU382671 & 5 \\
\hline MNC-3 & T. aestivum & Minnesota & GU382673 & 5 \\
\hline MNC-4 & T. aestivum & Minnesota & DQ417394 & 8 \\
\hline WA-2 & T. aestivum & Washington & DQ417395 & 8 \\
\hline DNM-1 & T. aestivum & Denmark & DQ417397 & 8 \\
\hline DNM-2 & T. aestivum & Denmark & DQ417404 & 8 \\
\hline TX-1 & T. aestivum & Texas & DQ417405 & 8 \\
\hline TX-2 & T. aestivum & Texas & DQ417406 & 8 \\
\hline \multicolumn{5}{|c|}{ Puccinia hordei } \\
\hline UO-5 & H. vulgare & Unknown & AY187089 & 5 \\
\hline \multicolumn{5}{|l|}{ P. recondita } \\
\hline UO-6 & H. vulgare & Unknown & EU014045 & 4 \\
\hline
\end{tabular}


used for molecular analyses. Representative voucher specimens were submitted to the U.S. National Fungus Collections (BPI) for each of the three Puccinia spp. sampled (BPI881580BPI1881582).

DNA manipulations. Spores were directly harvested from rustinfected tissue, placed in a $2-\mathrm{ml}$ microcentrifuge tube containing five or six 2-mm glass beads (BioSpec Products, Bartlesville, OK), and shaken in a BioSpec bead-beater on the medium setting for 6 min. Extraction buffer $(2 \times$ STE $[1 \times=100 \mathrm{mM} \mathrm{NaCl} ; 50 \mathrm{mM}$ Tris, $\mathrm{pH} 8.0$; and $1 \mathrm{mM}$ EDTA], $2 \%$ sodium dodecyl sulfate, and $2 \% \beta$ mercaptoethanol) was added to create a slurry that was mixed with $1 \times$ volume phenol. After ethanol precipitation of the supernatant, pelleted DNA was resuspended in Tris-EDTA (TE) buffer (1 M Tris [pH 8.0] and 0.5 M EDTA) and incubated at $37^{\circ} \mathrm{C}$ with RNaseA (1 $\mu \mathrm{g} / \mathrm{ml}$ ) for $30 \mathrm{~min}$. After an additional phenol:chloroform extraction and ethanol precipitation, pellets were resuspended in TE and DNA concentration and purity was determined using a NanoDrop 1000 Spectrophotometer (Wilmington, DE).

PCR primers ITS4 and ITS5 (44) were used to amplify the complete nuclear ribosomal ITS1, 5.8S, and ITS2 regions, including partial flanking regions of the $18 \mathrm{~S}$ and $28 \mathrm{~S}$ rDNA. All samples were amplified in a GeneAmp Thermocycler (Applied Biosystems, Foster City, CA) using cycling conditions previously described (16). Amplicons were excised from $0.8 \%$ agarose gels, purified using the GeneClean III Kit (QBiogene, Irvine, CA), ligated into pGEM-T Easy vectors (Promega Corp., Madison, WI), and transformed into $\alpha$-Select Gold Efficiency competent cells (BioLine, Taunton, MA) to account for (i) mixed rust species that may be present in the samples or (ii) dikaryon genome heterogeneity. At least three clones from each isolate were selected for sequencing. Insert sequences were generated from plasmid DNA purified with the Qiaprep Spin Miniprep Kit (Qiagen, Valencia, CA). Sanger sequencing was performed on both strands by GeneWiz, Inc. (South Plainfield, NJ) from the SP6 and T7 primer sites located on the vector. Sequences were assembled using Lasergene Sequence Analysis Software (DNASTAR, Inc., Madison, WI). Sequences were deposited in National Center for Biotechnology Information GenBank (http://www.ncbi.nlm.nih.gov/) (accession numbers GU598047 to GU598112).

Phylogenetic analyses. Two phylogenetic analyses were performed using the ITS sequences generated from this study, along with 49 additional sequences from grass hosts obtained from GenBank (Table 1). Only sequences associated with publication in a peer-reviewed journal were chosen for inclusion in this study. $P$. hordei and $P$. recondita were used as outgroup taxa for an analysis inclusive of all sampled taxa $(1,45)$. $P$. graminis was used as the outgroup for the analysis of a dataset composed entirely of $P$. coronata sequences (45).

Sequences were aligned using Clustal X2 (30), with gaps and ambiguous regions adjusted manually and reintroduced to the data set as single-state characters where positional homology could be assessed.

A distance matrix was created using PAUP 4.0b10 (42) to identify duplicate sequences, with one representative of each group retained for phylogenetic analysis. Phylogenetic analysis was performed using BEAST v1.4.8 (20) with a GTR + I + $\gamma$ model, empirical base frequencies, four gamma categories, and a relaxed lognormal molecular clock. The Yule process speciation prior was set as the means of speciation. For the analyses to reach convergence, the complete dataset was run for $100,000,000$ generations and the $P$. coronata analysis for 10,000,000 generations. Burn-in was evaluated using Tracer v1.4 (http://beast.bio.ed.ac.uk/Tracer), with the first 10,000 trees discarded from the complete rust fungus analysis and the first 1,000 trees from the $P$. coronata analysis. TreeAnnotator v1.4.8 (http://beast.bio.ed.ac.uk/TreeAnnotator) was used to select for the maximum clade credibility tree for each analysis. Posterior probability summaries were calculated for all nodes that had a posterior probability greater than 0.5 . Finished tree files were visualized in FigTree v1.2.3 (http://tree.bio.ed. ac.uk/software/figtree/).

Real-time PCR for species identification. Real-time PCR hydrolysis probes were designed for each of the three rust fungal species identified in this study. A complete list of new primers and probes developed can be found in Table 2. Probes PuSTM-ITS1 for $P$. graminis and PuSTR-ITS1 for $P$. striiformis were designed in the ITS1 region and were optimized for use with forward and reverse primers FrITS1Pu and RrITS1Pu. A $P$. coronata probe, PuCRITS2, was designed in the ITS2 region in combination with primers FrITS2Cr and RrITS2Cr. PuSTR-ITS1 was labeled on the $5^{\prime}$ end with the fluorescent reporter dye 6-carboxy-fluorescein (FAM) and on the $3^{\prime}$ end with the fluorescent quencher dye Black Hole Quencher 1 (BHQ-1) (IDT, Coralville, IA). PuSTM-ITS1was labeled with the $5^{\prime}$ fluorescent reporter dye cyanine $3(\mathrm{Cy} 3)$ and the $3^{\prime}$ quencher BHQ-2 (IDT), allowing for multiplexing with PuSTRITS1. PuCR-ITS2 was labeled on the $5^{\prime}$ end with the fluorescent reporter dye FAM and on the $3^{\prime}$ end with the fluorescent quencher dye Iowa Black Fluorescent Quencher (IBFQ) (IDT). An additional internal quencher, ZEN (IDT), was positioned in the center of the PuCR-ITS2 probe when this modification became available from the manufacturer to enhance specificity. Two additional primer/probe sets, PgFAM1 and PsFAM2, previously designed for detection of $P$. graminis $\mathrm{f}$. sp. tritici and $P$. striiformis from cereal crops (8), respectively, were synthesized for comparison with the turfgrass rust primers and probes developed in this study. Both primer/probe sets also detected select sequences in the ITS1 region and were labeled on the $5^{\prime}$ end with the fluorescent reporter dye FAM and the quencher BHQ- 1 on the $3^{\prime}$ end.

Positive controls were generated by synthesizing long oligonucleotides corresponding with the 218- or 219-bp or 198-bp region amplified in the real-time assays for each fungal species in the pUC57 plasmid vector (GeneWiz, Inc.). By synthesizing each species' ITS amplicon in their own pUC57 plasmid vector, we ensured that positive controls did not contain mixed DNA concentrations of the three rust fungal species, as may occur when using samples collected in the field as positive controls. To avoid overloading the reaction with plasmid template DNA, positive-control plasmid DNA at $15 \mathrm{ng} / \mu \mathrm{l}$ was mixed with an equal part of sheared salmon sperm DNA (Invitrogen, Carlsbad,

Table 2. Polymerase chain reaction primers and hydrolysis probes developed in this study

\begin{tabular}{|c|c|c|c|}
\hline Primer/probe $^{\text {a }}$ & Description & Sequence $\left(5^{\prime}-3^{\prime}\right)^{b}$ & Location (bp) \\
\hline FrITS2Cr & Puccinia coronata forward ITS2 & TTTGTGGATGTTGAGTGTTGC & $465-485^{\mathrm{c}}$ \\
\hline $\operatorname{RrITS} 2 \mathrm{Cr}$ & $P$. coronata reverse ITS2 & TCCCACCTGATTTGAGGTCT & $644-663^{c}$ \\
\hline FrITS1Pu & $P$. graminis and $P$. striiformis forward ITS1 & CCTGCGGAAGGATCATTATT & $37-56^{\mathrm{d}}$ \\
\hline RrITS1Pu & $P$. graminis and $P$. striiformis reverse ITS1 & TTTGGTTACATTCATTTAAACTTGTG & $230-255^{\mathrm{d}}$ \\
\hline PuCR-ITS2 & Puccinia coronata probe & FAM-TACTTGCCA-ZEN-TCTTTTGAAAGGAGGGA-IBFQ & $587-612^{c}$ \\
\hline PuSTM-ITS1 & Puccinia graminis probe & Су3-TTAGAGTGCACTTTATTGTGGCTCAACTCTCT-BHQ2 & $64-95^{\mathrm{d}}$ \\
\hline PuSTR-ITS1 & Puccinia striiformis probe & FAM-CGTAACTTCTTTATTGAATGTTGCATTACCCTCCC-BHQ1 & $160-194^{\mathrm{d}}$ \\
\hline
\end{tabular}

a ITS = internal transcribed spacer.

${ }^{\mathrm{b}}$ FAM = 6-carboxy-fluorescein fluorescent reporter dye, ZEN = internal quencher to enhance specificity, IBFQ = Iowa Black Fluorescent Quencher, Cy3 = cyanine 3 fluorescent reporter dye, BHQ-2 = Black Hole Quencher 2, and BHQ-1 = Black Hole Quencher 1 (IDT, Coralville, IA).

${ }^{\mathrm{c}}$ Primer/probe set base pair position in ITS2.

d Primer/probe set base pair position in ITS1. 
CA). A previously designed real-time PCR primer/probe set, StdLSU1, specific to the fungal large subunit region, served as an internal standard control (8).

Real-time PCR reactions were performed using a Cepheid SmartCycler (Cepheid, Sunnyvale, CA) in 25- $\mu$ l Cepheid tubes. Cepheid's Smartmix HM lyophilized PCR master mix was used for all optimization reactions, and Roche's Light Cycler 480 Probes master mix (Indianapolis, IN) was used for 96-well plate assays on the Step One Plus system (Applied Biosystems). Optimal cycling conditions were determined by using concentration gradients of 10 to $1 \mu \mathrm{M}$ of primers and probes at different annealing temperatures $\left(54\right.$ to $\left.60^{\circ} \mathrm{C}\right)$, and the cycle with the earliest detection was retained for all further analysis. The final reaction volumes contained $5 \mu \mathrm{l}$ of DNA and $20 \mu \mathrm{l}$ of Cepheid master mix, with $10 \mu \mathrm{M}$ both primers and $1 \mu \mathrm{M}$ probe. Final cycling conditions were as follows: initial denaturation at $95^{\circ} \mathrm{C}$ for $120 \mathrm{~s}$, followed by 45 cycles of $95^{\circ} \mathrm{C}$ for $3 \mathrm{~s}$ and $60^{\circ} \mathrm{C}$ for $39 \mathrm{~s}$. Manual threshold fluorescent units were set to 30 for $P$. graminis and 5 for $P$. striiformis and P. coronata.

Each probe was evaluated for specificity by testing all samples against each probe in a 96-well format, with each run replicated three times (Supplementary Table 1). Each sample was also screened using probes Pg FAM-1 and Ps FAM-2 (8), designed for detection of $P$. graminis $\mathrm{f}$. sp. tritici and $P$. striiformis in wheat. Probes were considered specific if cycle threshold $\left(C_{T}\right)$ values were zero for non-target DNA and water controls.
Assay sensitivity was determined by generating 10 -fold dilutions of genomic DNA until target DNA could not be detected, with concentrations between $3 \mathrm{pg} / \mu \mathrm{l}$ and $40 \mathrm{ng} / \mu \mathrm{l}$. Assays were further examined by preparing reactions containing DNA extracted from $50,100,150,200$, and 300 individual urediniospores for each of the species to determine lower detection limits. Standard curves were generated using the SmartCycler (Cepheid) software to estimate quantities of DNA in unknown samples and to calculate reaction efficiency.

\section{Results}

Phylogenetic identification of turf rust species based on the ITS gene tree. In fall 2008, 66 turfgrass samples exhibiting symptoms of rust disease were collected from 13 U.S. states and four countries (Table 1). Phylogenetic analysis of the ITS-5.8S rDNA region identified $P$. coronata, $P$. graminis, and $P$. striiformis (Fig. 1) from infected leaf tissue. Based on their placement in the phylogeny in monophyletic groups along with the ITS sequences from exemplar isolates of cereal rust fungi, $67 \%$ of the turf samples were identified as $P$. coronata, $28 \%$ as $P$. graminis, and $5 \%$ as $P$. striiformis (Table 1; Figs. 1 and 2). P. coronata was found on seven different grass hosts: bromegrass (Bromus sp.), tufted hair grass (Deschampsia sp.), Kentucky bluegrass, perennial ryegrass, reedgrass (Calamagrostis sp.), tall fescue (Festuca arundinacea Schreb.), and zoysia grass (Zoysia sp.) (Table 1). In contrast, $P$. graminis was identified on a much smaller host range, consisting

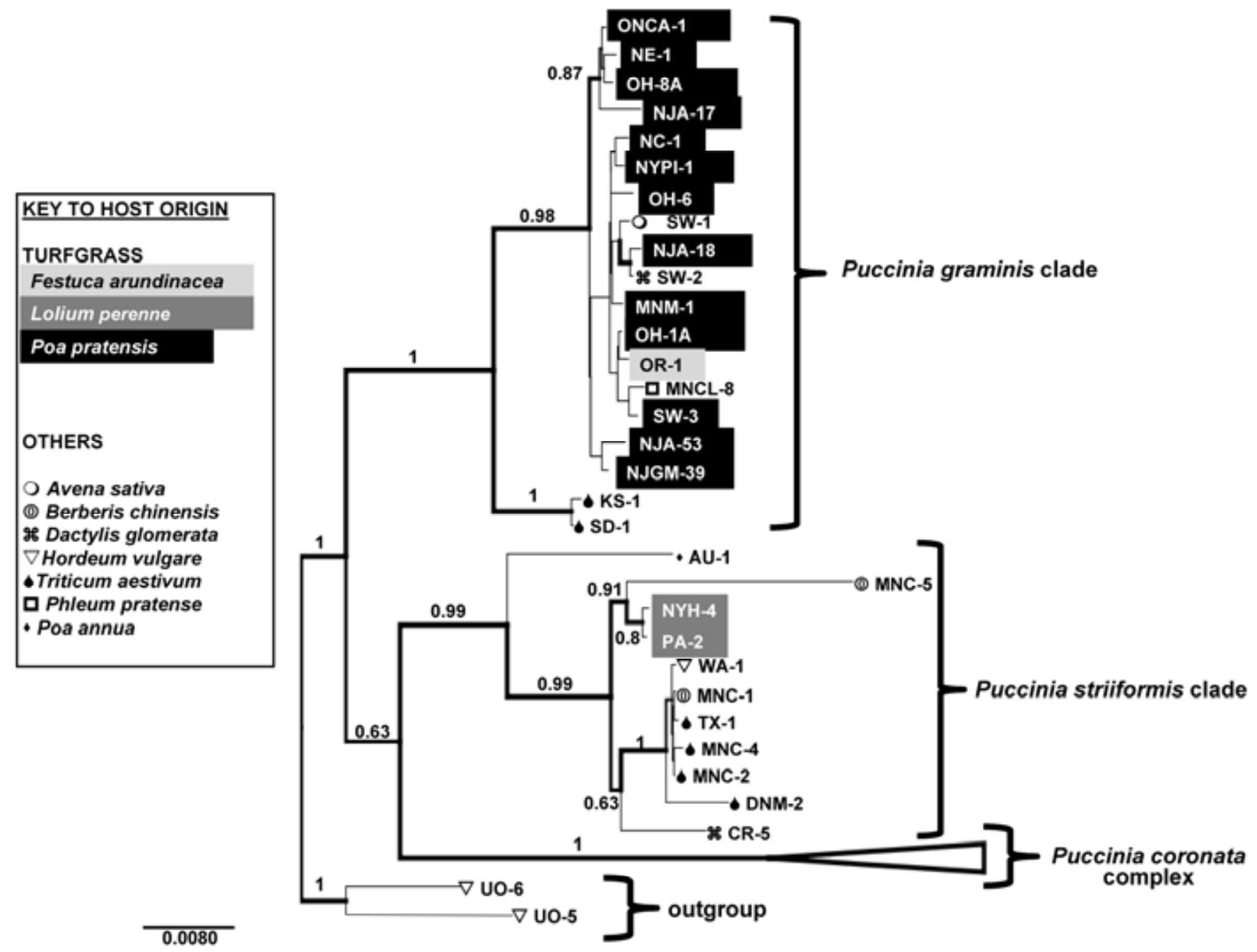

Fig. 1. Maximum clade credibility Bayesian phylogenetic tree generated from sequences of the internal transcribed spacer-5.8S rDNA region of the three Puccinia spp. identified on turfgrass hosts in this study: Puccinia coronata, $P$. graminis, and $P$. striiformis. The $P$. coronata complex is expanded in Figure 2 . Posterior probabilities $>50 \%$ supporting the topology are represented by thick black lines and numerical values. Symbols next to taxa indicate host plant origin. Branch lengths are proportional to levels of sequence divergence. The tree is rooted using the outgroup taxa $P$. hordei and $P$. recondita. 
of tall fescue and Kentucky bluegrass. P. striiformis was identified on only two grass hosts, perennial ryegrass and annual bluegrass (Poa аппиа L.).

All three rust fungal species formed well-supported monophyletic groups, with posterior probabilities $\geq 0.99$ (Fig. 1). Within the three species clades, the turfgrass isolates clustered together and were separate from isolates from non-turf gramineous hosts (posterior probabilities $\geq 0.91$ ). Within these divisions, there was no segregation based on geography, although sampling was not designed to test geographic distribution. Puccinia striiformis isolate AU-1, the only isolate in the study from Australia, diverged earlier in the phylogenetic tree than other members of the species but sampling was insufficient to determine whether this diversity reflected the unique geographic origin of this isolate relative to other isolates in the sample.

Several turfgrass samples within $P$. coronata and $P$. graminis formed well-supported subgroupings within their respective clades (Figs. 1 and 2); however, there were only four of these subgroups. Overall, outside of the division between cereal and turf samples in each of the three species, little intraspecific variation was observed.

Real-time PCR identification of turfgrass rust species. The application of host plant association and spore phenotype characters incorrectly identified $42 \%$ of the rust fungus samples (Supplementary Table 2), with over half of these misidentifications coming from samples of rust fungi on Kentucky bluegrass. Using classical field identification techniques, $58 \%$ of the samples from Kentucky bluegrass would have been identified as $P$. striiformis using pustule phenotype or $P$. graminis using host plant association, instead of $P$. coronata as verified by ITS sequence data. Other misidentifications occurred where $P$. coronata and $P$. striiformis could not be accurately differentiated on hosts other than Kentucky bluegrass.

Using existing real-time PCR protocols developed for $P$. graminis f. sp. tritici and $P$. striiformis from wheat to discriminate between turfgrass samples in our study (8), results were variable. Data using the $P$. graminis probe Pg-FAM-1 were more reliable than data using the $P$. striiformis Ps-FAM-2 probe, which frequently produced false positives. However, neither probe

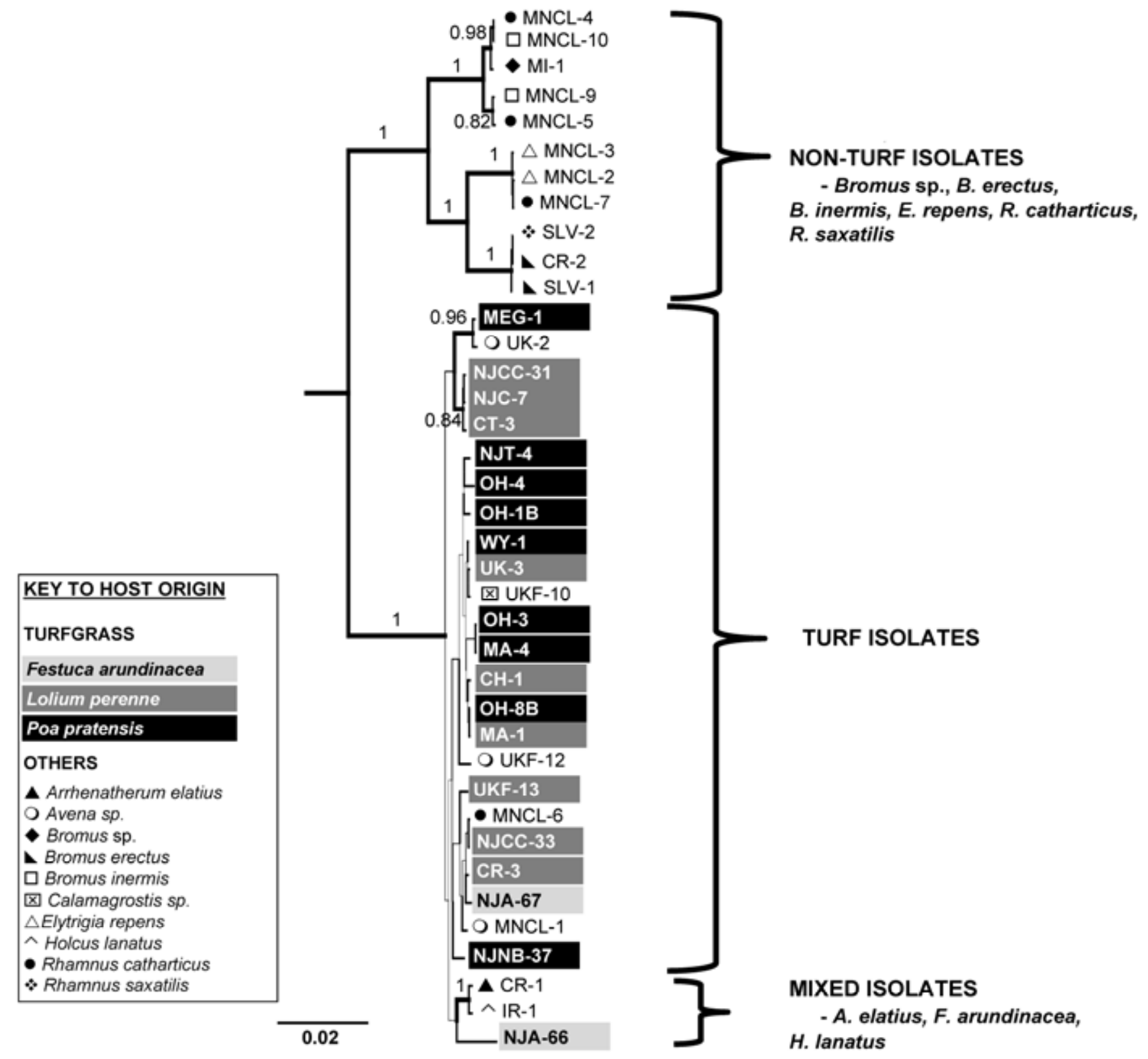

Fig. 2. Maximum clade credibility Bayesian phylogenetic tree generated from sequences of the internal transcribed spacer-5.8S rDNA region of the Puccinia coronata samples identified on turfgrass hosts in this study. Posterior probabilities $>50 \%$ supporting the topology are represented by thick black lines and numerical values. Symbols next to taxa indicate host plant origin. Branch lengths are proportional to levels of sequence divergence. The tree is rooted using the outgroup taxa $P$. graminis. 
consistently identified the different turf rust fungal species correctly. The existing Pg-FAM-1 probe sequence contained one unique single-nucleotide polymorphism (SNP) not found in $P$. graminis turfgrass isolates, located at position 5 in the probe region. The Pg-FAM-1 probe sequence was also not found in $P$. coronata or $P$. striiformis samples from turfgrass. Ps-FAM-2 was identical in sequence to $P$. striiformis samples NYH-4 and PA-2; however, the sequence was not found in sample AU-1, thus limiting its application for the detection of all $P$. striiformis isolates from turf. Therefore, we used the ITS sequence from our phylogenetic analyses to develop a real- time PCR diagnostic assay specifically designed for identification of turfgrass associated rust fungus species.

Fluorescence-labeled hydrolysis probes and primer pairs for use in real-time PCR experiments were designed using the ITS sequence alignment as a template to identify variable sites between the three Puccinia spp. associated with turf-type graminae hosts. Two probes, PuSTR-ITS1 and PuSTM-ITS1, were designed within the ITS1 region to detect $P$. striiformis and $P$. graminis. The probe region differed among the three species associated with turf-type gramineous hosts by at least 2 SNPs. The primer and probe binding sites for PuSTR-ITS1 and PuSTMITS1 in both turfgrass isolates and representative cereal isolates are illustrated in Figure 3. These probes were positioned within a 219-bp PCR amplicon that would be generated by the same primer pair for both species (Table 2).

Two attempts were made to also design a probe for $P$. coronata within the same ITS1 amplicon used for $P$. graminis and $P$. striiformis but neither of these probes produced acceptable levels of fluorescence or repeatable results (data not shown). Therefore, a probe for detection of $P$. coronata, PuCR-ITS2, was designed in the ITS-2 region, positioned within a 199-bp PCR amplicon that contained a 6-bp deletion specific to turfgrass isolates of $P$. coronata (Fig. 4). When used to screen samples in the current study, real-time PCR analysis showed that each probe accurately identified samples from the target species. A summary of these data is found in Supplementary Figure $1 \mathrm{~A}-\mathrm{C}$. Non-target DNA and negative controls produced $\mathrm{C}_{\mathrm{T}}$ values $=0$. Detection using PuSTRITS1 began at 50 urediniospores $\left(\mathrm{C}_{\mathrm{T}}=32.74\right)$, PuSTM-ITS1 at 150 spores $\left(\mathrm{C}_{\mathrm{T}}=36.62\right)$, and PuCR-ITS2 at 150 urediniospores $\left(\mathrm{C}_{\mathrm{T}}=\right.$ 34.42). Assay sensitivity determined by serial dilutions of genomic DNA showed the lowest levels of detection to be between 1 and 9 pg (Fig. 5). Positive controls that were synthesized in the pUC57 plasmid vector repeatedly produced fluorescence early in the PCR cycle, with $\mathrm{C}_{\mathrm{T}}$ values of 20 to 25 . Biological samples generated fluorescence curves later in the cycle, with $\mathrm{C}_{\mathrm{T}}$ values of 27 to 38 , and increased with decreasing DNA concentrations. Nonspecific positive reactions were observed from four targets $(\mathrm{OH}-1 \mathrm{~A} / \mathrm{B}$ and OH-8A/B); however, additional DNA sequencing of cloned ITS amplicons established the presence of both $P$. coronata and $P$. graminis in these samples.

Probes PuSTR-ITS 1 and PuSTM-ITS 1 were designed within the same primer set to allow multiplexing of the two probes with one another for simultaneous detection of $P$. graminis and $P$. striiformis. When screened against $P$. graminis and $P$. striiformis synthesized positive controls, the multiplex reaction successfully detected both positive controls at a $C_{T}$ value $\left(C_{T}=19.73\right.$ and 18.11, respectively) comparable with non-multiplexed reactions (Fig. 6). The multiplexed reaction was also successful at detecting rust species from turfgrass samples collected in the field that were suspected of having rust infection. Detection was between $\mathrm{C}_{\mathrm{T}}$ values of 21.60 and 23.97 (Fig. 6).

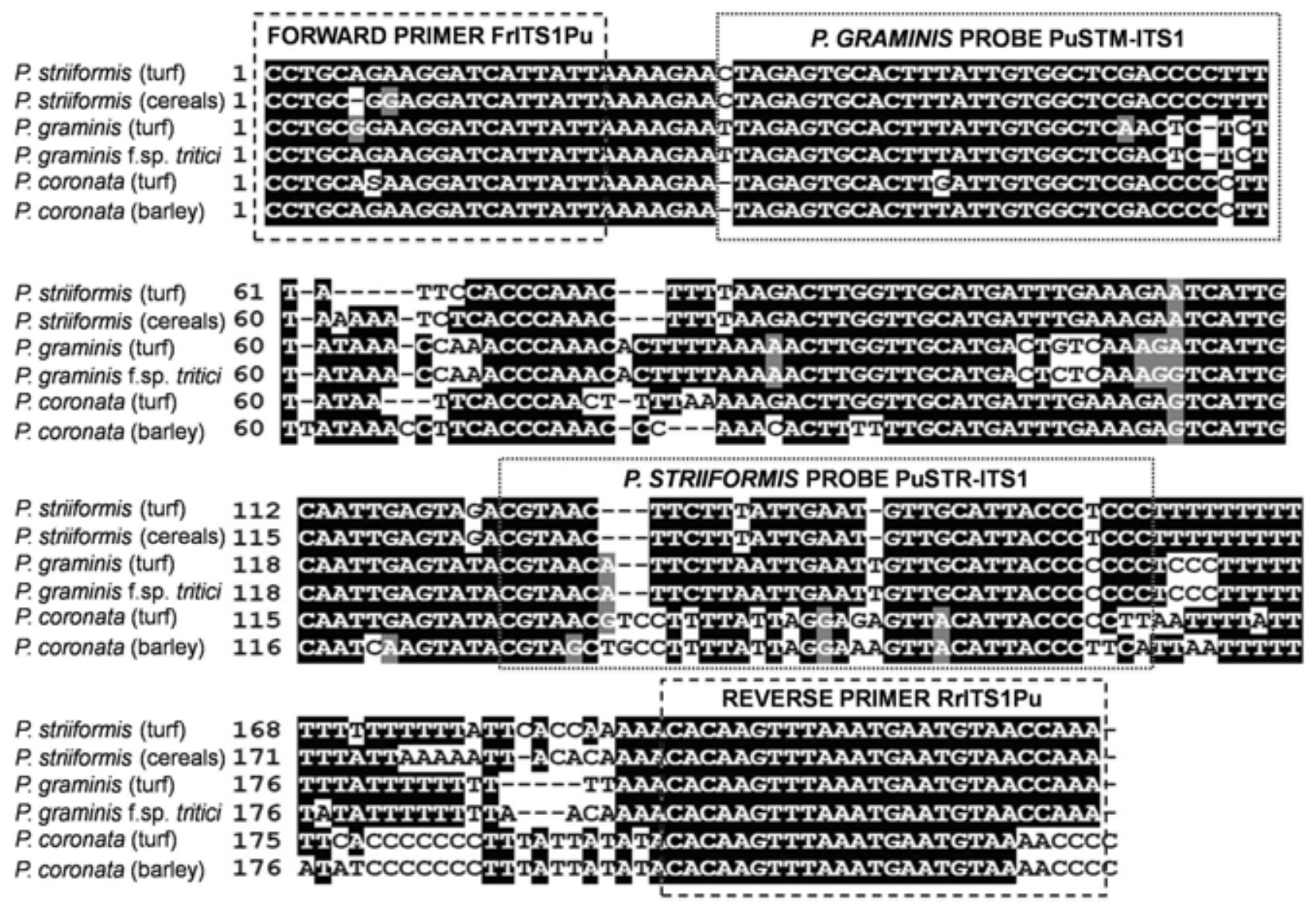

Fig. 3. Alignment diagram of the partial rDNA internal transcribed spacer 1 (ITS1) region showing the placement of polymerase chain reaction primers FrlTS1Pu and RrITS1Pu with Puccinia graminis probe PuSTM-ITS1 and P. striiformis probe PuSTR-ITS1. Representative samples from P. coronata, P. graminis, and P. striiformis on turfgrass and cereal crop hosts are included in the alignment. Species-specific single-nucleotide polymorphisms (SNPs) differentiating species are denoted by gray and white shading. Probe binding sites differed between the three turfgrass rust fungi by at least 2 SNPs. Numbers next to species names represent nucleotide base pair positions. 


\section{Discussion}

The primary objective of this study was to evaluate fungal species responsible for rust disease of turfgrasses using molecular phylogenetic analysis. From 66 diseased grass samples, three rust fungi were identified: $P$. coronata, $P$. graminis, and $P$. striiformis. All three of these fungi have been previously identified through spore morphology as causing rust on turfgrass hosts (18); however, this research is the first evaluation of turf rust fungi using molecular data. Two other species described as causing turfgrass rust diseases in temperate regions, $P$. brachypodii and $P$. recondita, were not identified in the current study with either morphological or phylogenetic analysis.

From an evolutionary perspective, all three species formed distinct monophyletic groups and were subdivided broadly according to host plant origin, in agreement with the findings of Zambino and Szabo (45). Our data showed no pattern of segregation based on locale in any of the clades, suggesting that turfgrass populations of these fungi are widespread and highly mobile, as is known to occur in the wheat stem rust pathosystem (29). Population-scale investigations are needed to test this idea further, because the sampling and molecular markers used in the present research were not designed to address distribution patterns.

In our analyses, subspecific groups corresponding to a split between $P$. graminis f. sp. tritici and $P$. graminis sampled from all other hosts were recovered, an organization that has also been observed in previous research using ITS sequence data (1). Differentiation of the ITS sequences between these subspecific groups was well-supported by posterior probabilities, with 20 SNPs and 6 insertion/deletion events in the IT1 and ITS2 regions supporting these groups. In studies of $P$. graminis using an ITS gene tree, Abbasi and colleagues (1) put forth the idea that these subspecific groups might be recategorized as two distinct species but, to date, this possibility has not been robustly tested through comprehensive sampling of the fungus and multilocus phylogenetic studies capable of systematically identifying species boundaries.

Similarly, the $P$. striiformis clade was subdivided into two major groups: a perennial ryegrass group and a wheat/barley group. The subdivision of $P$. striiformis into separate species has yet to be adopted by many researchers, and standard forma speciales nomenclature continues to be applied $(6,15,21,24,25)$. The recent description of four strongly supported monophyletic lineages within $P$. striiformis supports division of the species to $P$. striiformis sensu stricto on members of Triticeae, P. pseudostriiformis on bluegrass, $P$. striiformoides on orchard grasses (Dactylis sp.), and $P$. gansensis on needlegrass (Achnatherum sp.) $(2,32)$. Though sampling within the family Poaceae in this study was limited to perennial ryegrass and annual bluegrass, we found strong posterior probability support $(>0.63)$ for subdivisions of $P$. striiformis on members of Triticeae, orchard grass, and cultivated turfgrass hosts,

\section{P. striiformis (turf) \\ $P$. striformis (cereals) \\ $P$. coronata (turf) \\ $P$. coronata (barley) \\ $P$. graminis (turf) \\ P. graminis f.sp. tritici}

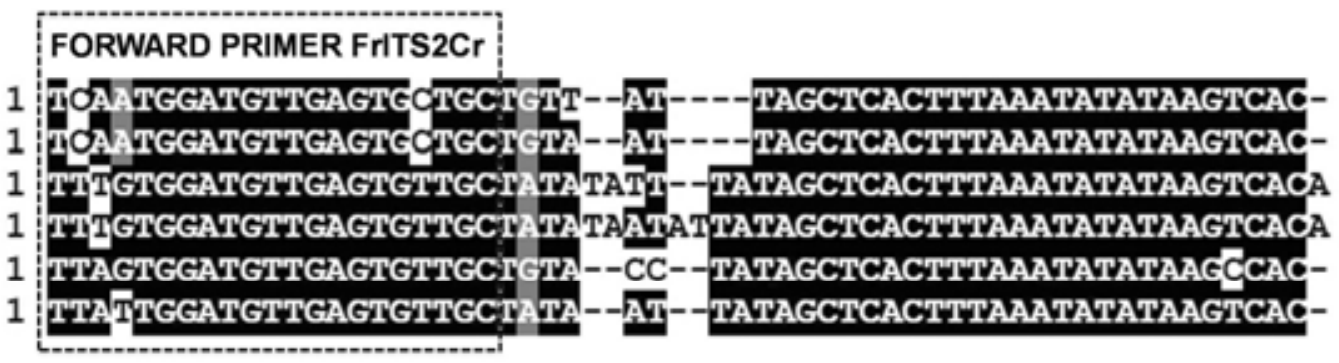

\section{P. striiformis (turf) \\ $P$. striformis (cereals) \\ $P$. coronata (turf) \\ $P$. coronata (barley) \\ P. graminis (turf) \\ P. graminis f.sp. tritici}

\section{P. striiformis (turf) \\ $P$. striformis (cereals) \\ $P$. coronata (turf) \\ $P$. coronata (barley) \\ P. graminis (turf) \\ P. graminis f.sp. tritici}
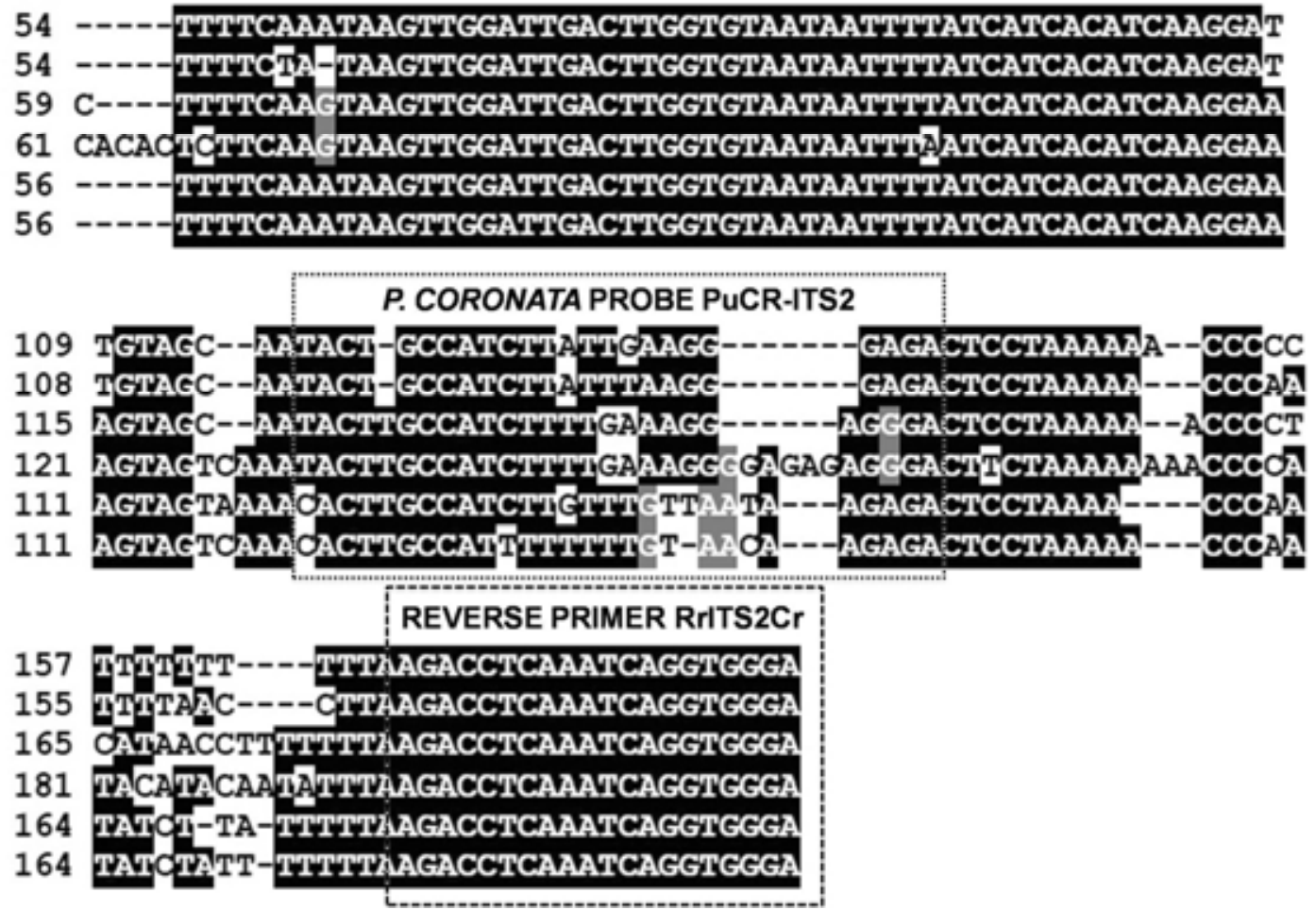

Fig. 4. Alignment diagram of the rDNA internal transcribed spacer 2 (ITS2) region showing the placement of polymerase chain reaction primers FrITS2Cr and RrITS2Cr with Puccinia coronata probe PuCr-ITS2. Representative samples from $P$. coronata, $P$. graminis, and $P$. striiformis on turfgrass and cereal crop hosts are included in the alignment. Species-specific single-nucleotide polymorphisms (SNPs) differentiating species are denoted by gray and white shading. Probe binding sites differed between the three turfgrass rust fungi by at least 5 SNPs. Numbers next to species names represent nucleotide base pair positions. 
consistent with the groupings by Liu and Hambleton (32). Although this suggests that $P$. striiformis isolates from perennial ryegrass may, in fact, be properly placed within $P$. pseudostriiformis, more robust sampling is needed to confirm the exact taxonomic position of perennial ryegrass isolates relative to those from bluegrass hosts. With the recent identification of barberry (Berberis spp.) as the alternate host of $P$. striiformis f. sp. tritici (syn. P. striiformis sensu stricto) and P. striiformis f. sp. poae (syn. P. pseudostriiformis) (27), it is likely that future research will serve to more clearly define the relationships and boundaries that exist between $P$. striiformis sensu lato pathotypes, genetic populations, and differentiated species, as well as the methodologies used to discriminate between these entities.

Within the $P$. coronata phylogeny, two major subdivisions were observed: a group comprising samples from non-turfgrass hosts and a second group largely composed of rust fungal samples from turfgrass hosts (Fig. 2). In the turfgrass clade, additional subspecific clustering was also observed but these groups were not sup-
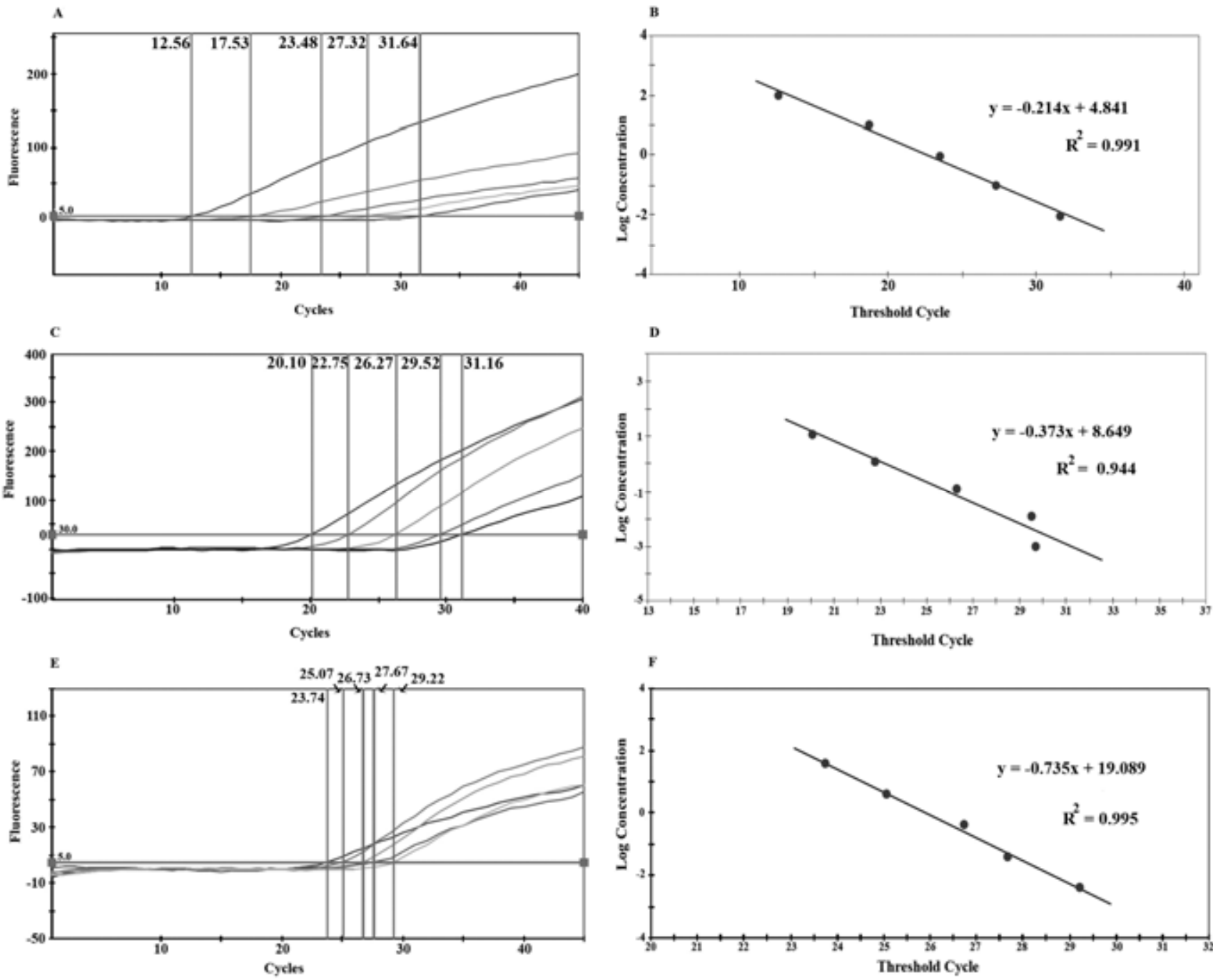

Fig. 5. Real-time polymerase chain reaction data with 10-fold dilutions showing decreased fluorescence as sample concentration decreases (left) and standard curve showing the straight line relationship between the log of known DNA concentrations and the second derivative threshold cycle value (right). ITS = internal transcribed spacer $\mathbf{A}$ and $\mathbf{B}$, Puccinia coronata probe PuCr-ITS2 with lower detection limit of $9 \mathrm{pg} ; \mathbf{C}$ and $\mathbf{D}, P$. graminis probe PuSTM-ITS1 with lower detection limit of $1 \mathrm{pg}$; and $\mathbf{E}$ and $\mathbf{F}, P$. striiformis probe PUSTR-ITS1 with lowest detection limit of $4 \mathrm{pg}$.
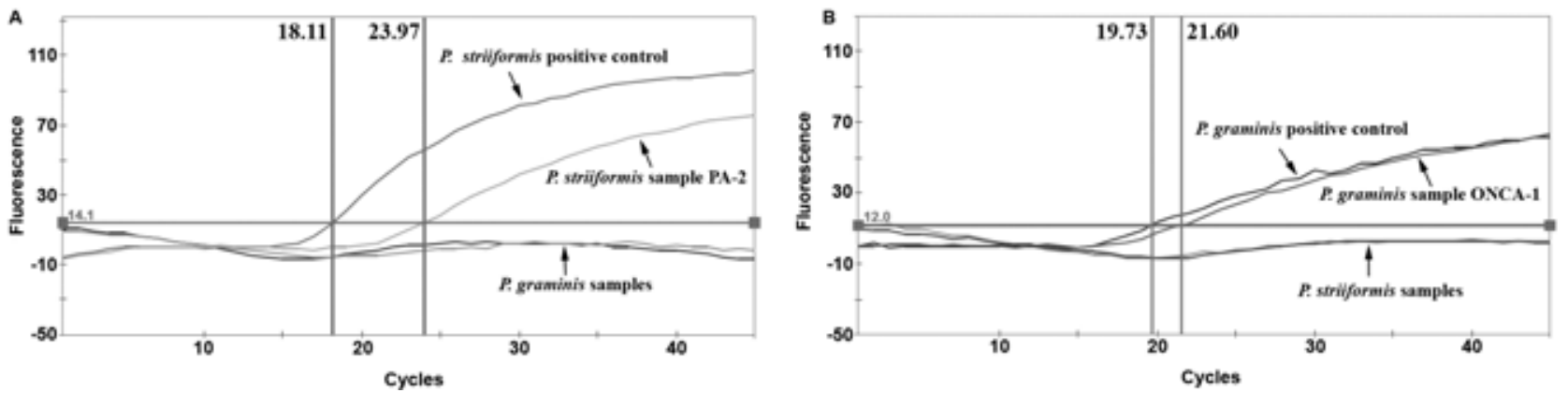

Fig. 6. Real-time polymerase chain reaction data with Puccinia graminis probe PuSTM-ITS1 and P. striiformis probe PuSTR-ITS1 multiplexed in a single reaction tube using turfgrass samples. ITS = internal transcribed spacer. Only target of interest produced fluorescence in each multiplexed reaction. Positive control pUC57 samples are labeled. A, Fluorescence for the 6-carboxy-fluorescein-labeled probe PuSTR-ITS1 and B, fluorescence for the cyanine 3-labeled probe PuSTM-ITS1. 
ported through posterior probability estimates. In these subspecific clades, there was almost no supported resolution between samples, reflecting the high levels of sequence similarity. This similarity was confirmed when pairwise distances were calculated for the isolates. Intraspecific distances ranged between 0.00168 and 0.10774 , with $46 \%$ of the ITS sequences identical $(P=0.000001)$ to at least one isolate from the sample (data not shown).

Real-time PCR for the accurate and quick identification of turfgrass rust species. Identification of $P$. graminis infecting turfgrass samples through the use of spore color phenotype has been long considered a reliable process, because the pustules exhibit an easily distinguishable color that has been thought to separate the fungus from $P$. coronata and $P$. striiformis (40). Phenotypic identification of $P$. graminis from turf has also been used in conjunction with host association criteria, because the fungus was expected to be found in association with bluegrass but not ryegrass hosts $(40,43)$. Inaccurate identification of turfgrass rust fungi has been most commonly associated with the differentiation between $P$. coronata and $P$. striiformis, because the urediniospores exhibit a similar yellow-orange color and the characteristic linear nature of $P$. striiformis uredinial pustules can be difficult to distinguish on narrow leaf blades (32).

Real-time PCR has been previously shown to be effective for discrimination and detection of several rust fungi, including Phakopsora pachyrhizi, Puccinia graminis f. sp. tritici, P. kuehnii, $P$. melanocephala, $P$. polysora, $P$. recondita, $P$. sorghi, $P$. striiformis (from cereals), and $P$. triticina $(8,9,17,23,27)$. Although the ITS sequence data were not capable of identifying subspecific groups with any degree of confidence in our analysis, we were able to demonstrate the ability of the ITS region to accurately identify turfgrass rust fungi, and used the sequence data as the basis for the development of a real-time PCR protocol. Even minute amounts of DNA can be detected through this protocol (as little as 1 to $9 \mathrm{pg}$ or 50 to 150 urediniospores), with an accurate identification provided from DNA samples in only $30 \mathrm{~min}$. The assay was $97 \%$ reliable in its identification of $P$. graminis, $P$. coronata, and $P$. striiformis from turfgrass tissue; could detect the presence of multiple species in mixed infections; and, once implemented in the laboratory, can be routinely performed by turfgrass breeding programs, plant health practitioners, and diagnostic clinics with minimal training in molecular techniques. Already, the Plant Diagnostic Laboratory at Rutgers University is using the real-time PCR probes to identify turfgrass rust fungal species in support of breeding efforts at the University (R. Buckley and S. Tirpak, personal communication). The use of synthesized positive control DNA and multiplexing probes significantly reduces the number of steps needed to successfully implement this procedure and eliminates the need for the collection and validation of control samples of the three turfgrass rust fungi. This assay provides a way to rapidly and accurately identify turfgrass rust fungi and, thus, should become a valuable tool for diagnosticians as well as turfgrass managers seeking to control rust diseases in the future.

$P$. coronata as a widespread pathogen of Kentucky bluegrass. Traditionally, turfgrass breeders have used pustule phenotype and host plant identity to discriminate between rust pathogens in the field. Using this system, a red pustule phenotype would indicate stem rust and an orange phenotype crown or stripe rust. Crown and stripe rust have been further differentiated by the orientation of pustules along the leaf vein, with stripe rust pustules forming parallel to the host vein (40), although recent research has shown that orientation of the sorus is an unreliable feature (32). Using these criteria, stem rust caused by $P$. graminis has been the most frequently reported rust disease on Kentucky bluegrass, while crown rust caused by $P$. coronata has been the most common disease on ryegrass hosts $(40,43)$. However, it is now apparent that traditional phenotype and host association criteria are imprecise methods for the identification of fungi causing rust in turfgrass hosts, because our data showed $P$. coronata to be the most common rust pathogen on Kentucky bluegrass, and both $P$. graminis and $P$. striiformis were found in association with both rye and bluegrass hosts. Consequently, the breakdown of resistance to rust that was observed in Kentucky bluegrass during the past decade may not have occurred due to the emergence of new $P$. graminis races as originally hypothesized (10), a finding that is consistent with the long-term, stable race structure of $P$. graminis in the United States since the eradication of barberry across the Great Plains. Instead, our data support an alternative scenario: that the upsurge of rust disease in Kentucky bluegrass could be the result of an increased association of this grass with $P$. coronata. Kentucky bluegrass is a documented host of $P$. coronata in New Zealand, the United Kingdom, Poland, China, and the Czech Republic; however, this is the first published report of this host/fungus association from the western hemisphere (22). Nevertheless, $P$. coronata has occurred on Kentucky bluegrass in North America in the past, because our observations of herbarium specimens revealed the presence of the fungus at least as far back as the 19th century (e.g., herbarium specimen BPI060420 in the U.S. National Fungal Collections from Missouri, collected 30 October 1886). Whether this "novel" hostpathogen association is truly new or is a longstanding relationship that has gone unnoticed due to misidentification has yet to be resolved. Alternatively, the possibility that the fungus recently transitioned from another host population to Kentucky bluegrass cannot be ruled out and is, in fact, supported by the clustering of $P$. coronata isolates from Kentucky bluegrass, perennial ryegrass, and tall fescue with the pathogen from oat (Avena sativa L.; Fig. 2). Because $P$. coronata is highly variable (18), reports of the fungus causing new diseases in economically important grasses are not uncommon, as evidenced by its identification as a new pathogen of barley (Hordeum vulgare L.) (26) and smooth brome (Bromus inermis Leyss.) (19).

The identification of $P$. coronata as a common, widespread pathogen of Kentucky bluegrass is likely to have considerable impact on future turfgrass breeding efforts. Unlike with the $P$. graminis and $P$. striiformis pathosystems, the alternate host for $P$. coronata, common buckthorn (Rhamnus cathartica L.), is an invasive and widely distributed plant in North America, allowing $P$. coronata to complete its sexual cycle. As a result, in cereal pathosystems afflicted by $P$. coronata, new virulent races are continually evolving through genetic variation generated by sexual recombination and the rapid appearance of random mutations. For example, between 2001 and 2005, 383 unique races of $P$. coronata were documented from 680 oat samples in the United States, with mean virulence significantly increasing during this period (14). Such a scenario in Kentucky bluegrass could have far-reaching implications for the turfgrass industry but remains to be validated.

\section{Acknowledgments}

This research was funded by the Rutgers Center for Turfgrass Science and the New Jersey Agricultural Experiment Station. We thank N. Patel for her assistance in sample collection; I. Chivers, M. DaCosta, K. Entwistle, P. Harmon, J Inguagiato, M. Kennelly, J. Rimelspach, M. Thurn, M. Tomaso-Peterson, L. Tredway, and E. Watkins for supplying diseased samples; L. Szabo, J. Johnson, and the United States Department of Agriculture-Agricultural Research Service Cereal Disease Lab for sharing their knowledge of the cereal rusts; S. Bonos for helpful discussions; J. Polashock for comments on this manuscript, and D. Kobayashi and B. Hillman for use of their lab facilities.

\section{Literature Cited}

1. Abbasi, M., Goodwin, S. B., and Scholler, M. 2005. Taxonomy, phylogeny, and distribution of Puccinia graminis, the black stem rust: new insights based on rDNA sequence data. Mycoscience 46:241-247.

2. Abbasi, M., Hedjaroude, Gh. A., Scholler, M., and Goodwin, S. B. 2004 Taxonomy of Puccinia striiformis s. 1. in Iran. Rostaniha 5:71-82.

3. Aime, C. M. 2006. Toward resolving family-level relationships in rust fungi (Uredinales). Mycoscience 47:112-122.

4. Alaei, H., De Backer, M., Nuytinck, J., Maes, M., Höfte, M., and Heungens, K. 2009. Phylogenetic relationships of Puccinia horiana and other rust pathogens of Chrysanthemum $\times$ morifolium based on rDNA ITS sequence analysis. Mycol. Res. 113:668-683.

5. Anikster, Y., Szabo, L. J., Eilam, T., Manisterski, J., Koike, T., and Bushnell, W. R. 2004. Morphology, life cycle biology, and DNA sequence analysis of rust fungi on garlic and chives from California. Phytopathology 94:569-577.

6. Bahri, B., Kaltz, O., Leconte, M., de Vallavieille-Pope, C., and Enjalbert, J. 
2009. Tracking costs of virulence in natural populations of the wheat rust pathogen, Puccinia striiformis f. sp. tritici. BMC Evol. Biol. 9:26.

7. Barker, R. E., Pfender, W. F., and Welty, R. E. 2003. Selection for stem rust resistance in tall fescue and its correlated response with seed yield. Crop Sci. 43:75-79.

8. Barnes, C. W., and Szabo, L. J. 2007. Detection and identification of four common rust pathogens of cereals and grasses using real-time polymerase chain reaction. Phytopathology 97:717-727.

9. Barnes C. W., Szabo L. J., and Bowersox V. C. 2009. Identifying and quantifying Phakopsora pachyrhizi spores in rain. Phytopathology 99:328338 .

10. Bonos, S. A., Clarke, B. B., and Meyer, W. M. 2006. Breeding for disease resistance in the major cool-season turfgrasses. Annu. Rev. Phytopathol. 44:213-234.

11. Braverman, S. W. 1966. Sources of resistance to stem and leaf rust among Phleum species. Plant Dis. Rep. 50:849-851.

12. Britton, M. P., and Butler, J. D. 1965. Resistance of seven Kentucky bluegrass varieties to stem rust. Plant Dis. Rep. 49:708-709.

13. Bushnell, W. R. 1984. Structural and physiological alterations in susceptible host tissue. Pages 477-500 in: The Cereal Rusts: Origins, Specificity, Structure, and Physiology. W. R. Bushnell and A. P. Roelfs, eds. Academic Press, Orlando, FL.

14. Carson, M. L. 2008. Virulence frequencies in oat crown rust in the United States from 2001 through 2005. Plant Dis. 92:379-384.

15. Chen, W. Q., Wu, L. R, Liu, T. G., Xu, S. C., Jin, S. L., Peng, Y. L., and Wang, B. T. 2009. Race dynamics, diversity, and virulence evolution in Puccinia striiformis f. sp. tritici, the causal agent of wheat stripe rust in China from 2003-2007. Plant Dis. 93:1093-1101.

16. Crouch, J. A., Clarke, B. B., and Hillman, B. I. 2006. Unraveling evolutionary relationships among the divergent lineages of Colletotrichum causing anthracnose disease in turfgrass and corn. Phytopathology 96:46-60.

17. Crouch, J. A., and Szabo, L. J. 2011. Real-time PCR detection and discrimination of the southern and common corn rust pathogens Puccinia polysora and Puccinia sorghi. Plant Dis. 95:624-632.

18. Cummins, G. B. 1971. The Rust Fungi of Cereals, Grasses, and Bamboos. Springer-Verlag, New York

19. Delgado, N. J., Grau, C. R., and Casler, M. D. 2001. Host range and alternate host of a Puccinia coronata population from smooth brome grass. Plant Dis. 85:513-516.

20. Drummond A. J., and Rambaut, A. 2007. BEAST: Bayesian evolutionary analysis by sampling trees. BMC Evol. Biol. 7:214.

21. Duan, X., Tellier, A., Wan, A., Leconte, M., de Vallavieille-Pope, C., and Enjalbert, J. 2010. Puccinia striiformis f. sp. tritici presents high diversity and recombination in the over summering zone of Gansu, China. Mycologia 102:44-53.

22. Farr, D. F., and Rossman, A. Y. 2010. Fungal databases, Systematic Mycology and Microbiology Laboratory, ARS, USDA. http://nt.ars-grin.gov/ fungaldatabases/.

23. Glynn, N. C., Dixon, L. J, Castlebury, L. A., Szabo, L. J., and Comstock, J. C. 2010. PCR assays for the sugarcane rust pathogens Puccinia kuehnii and $P$. melanocephala and detection of a SNP associated with geographical distribution in P. kuehnii. Plant Pathol. 59:703-711.

24. Hovmoller, M. S., Yahyaoui, A. H., Milus, E. A., and Justesen, A. F. 2008. Rapid global spread of two aggressive strains of a wheat rust fungus. Mol. Ecol. 17:3818-3826.

25. Jafary, H., Szabo, L. J., and Niks, R. E. 2006. Innate nonhost immunity in barley to different heterologous rust fungi is controlled by sets of resistance genes with different and overlapping specificities. Mol. Plant-Microbe Interact. 19:1270-1279.

26. Jin, Y., and Steffesnson, B. J. 1992. Puccinia coronata on barley. Plant Dis. $76: 1283$

27. Jin, Y., Szabo, L. J., and Carson, M. 2010. Century-old mystery of Puccinia striiformis life history solved with the identification of Berberis as an alternate host. Phytopathology 100:432-435.

28. Kimbeng, C. A. 1999. Genetic basis of crown rust resistance in perennial ryegrass, breeding strategies, and genetic variation among pathogen populations: a review. Aust. J. Exp. Agric. 39:361-378.

29. Kolmer, J. A. 2005. Tracking wheat rust on a continental scale. Curr. Opin Plant Biol. 8:441-449.

30. Larkin, M. A., Blackshields, G., Brown, N. P., Chenna, R., McGettigan, P. A., McWilliam, H., Valentin, F., Wallace, I. M., Wilm, A., Lopez, R., Thompson, J. D., Gibson, T. J., and Higgins, D. G. 2007. Clustal W and Clustal X version 2.0. Bioinformatics 23:2947-2948.

31. Leonard, K. J., and Szabo, L. J. 2005. Stem rust of small grains and grasses caused by Puccinia graminis. Mol. Plant Pathol. 6:99-111.

32. Liu, M., and Hambleton, S. 2010. Taxonomic study of stripe rust, Puccinia striiformis sensu lato, based on molecular and morphological evidence. Fungal Biol. 114:881-899.

33. Maier, W., Wingfield, B. D., Mennicken, M., and Wingfield, M. J. 2007 Polyphyly and two emerging lineages in the rust genera Puccinia and Uromyces. Mycol. Res. 111:176-185.

34. Peterson, P. D. 2001. Stem Rust of Wheat: From Ancient Enemy to Modern Foe. American Phytopathological Society, St. Paul, MN.

35. Pfleger, F. L. 1973. Reaction of Poa pratensis introductions to Puccinia graminis. Plant Dis. Rep. 57:595-598.

36. Pfender, W. 2001. Host range differences between populations of Puccinia graminis subsp. graminicola obtained from perennial ryegrass and tall fescue. Plant Dis. 85:993-998.

37. Pfender, W. 2009. Demonstration of pathotype specificity in stem rust of perennial ryegrass. Phytopathology 99:1185-1189.

38. Potter, L. R., Cagas, B., Paul, V. H., and Birckenstaedt, E. 1990. Pathogenicity of some European collections of crown rust (Puccinia coronata Corda) on cultivars of perennial ryegrass. J. Phytopathol. 130:119-126.

39. Roelfs, A. P. 1988. Genetic control of phenotypes in wheat stem rust. Annu. Rev. Phytopathol. 26:351-367.

40. Smiley, R. W., Dernoeden, P. H., and Clarke, B. B. 2005. Rusts. Pages 4044 in: Compendium of Turfgrass Diseases, 3rd ed. American Phytopathological Society, St. Paul, MN.

41. Studer, B., Boller, B., Bauer, E., Posselt, U. K., Widmer, F., and Kolliker R. 2007. Consistent detection of QTLs for crown rust resistance in Italian ryegrass (Lolium multiflorum Lam.) across environments and phenotyping methods. Theor. Appl. Genet. 115:9-17.

42. Swofford, D. 2002. PAUP* Phylogenetic Analysis Using Parsimony (*And Other Methods). Version 4. Sinauer Associates, Sunderland, MA

43. Vargas, Jr., J. M. 2005. The Rusts. Pages 90-95 in: Management of Turfgrass Diseases. 3rd ed. John Wiley \& Sons, Inc., Hoboken, NJ.

44. White, T. J., Bruns, T., Lee, S., and Taylor, J. 1990. Amplification and direct sequencing of fungal ribosomal RNA genes for phylogenetics. Pages 315 322 in: PCR Protocols: A Guide to Methods and Applications. M. A. Innis D. H. Gelfand, J. J. Sninsky, and T. J. White, eds. Academic Press, San Diego, CA

45. Zambino, P. J., and Szabo, L. J. 1993. Phylogenetic relationships of selected cereal and grass rusts based on rDNA sequence analysis. Mycologia $85: 401-414$. 